\title{
On sustainable improvements of agricultural practices in the Bairrada region (Portugal)
}

\author{
Maria C. Cunha ${ }^{1} \cdot$ Dalila Serpa $^{2} \cdot$ João Marques ${ }^{1} \cdot$ Jan J. Keizer $^{2} \cdot$ Nelson Abrantes $^{2}$
}

Received: 1 April 2021 / Accepted: 20 January 2022 / Published online: 11 February 2022

(C) The Author(s) 2022

\begin{abstract}
The objective of this paper is to develop a framework to overcome problems of soil nutrient legacies and poor quality of water bodies raised by agricultural practices. A multicriteria decision analysis (MCDA) approach is proposed to evaluate different alternatives to help to define sustainable vineyard agricultural solutions. The methodology developed was applied to a basin in the north-central part of Portugal, the São Lourenço basin. The land cover of the basin consists predominantly of vines. A number of alternatives based on different vineyard management practices and land use are evaluated against environmental and socioeconomic criteria by means of the soil and water assessment tool (SWAT) model and considering information included in some databases. The preference ranking organization method for enrichment evaluation (PROMETHEE) outranking method is used to rank the alternatives and to evaluate weight stability intervals assigned to criteria. A supplementary analysis is performed by a different MCDA method (technique for order of preference by similarity to ideal solution (TOPSIS)), belonging to the family of compensatory methods, to provide additional insights to the decision makers. The results show the best and the worst alternatives for vineyard agricultural practices according to the weights assigned to the criteria. The sensitivity analysis of the weights indicated most stable ranking cases and the criterion that presents the narrow stability intervals. This work offers the opportunity to discuss comparisons between different types of agricultural practices and give insights for future developments of other areas where intensive vineyard cultivation is implemented.
\end{abstract}

Keywords Multicriteria decision analysis - Agricultural management practices · Vineyards $\cdot$ Nutrient legacies $\cdot$ PROMETHEE, TOPSIS

Maria C. Cunha

mccunha@dec.uc.pt

1 University of Coimbra, CEMMPRE, Department of Civil Engineering, Polo 2, 3030-788 Coimbra, Portugal

2 CESAM \& Department of Environment and Planning, University of Aveiro, Campus de Santiago, 3810-193 Aveiro, Portugal 


\section{Introduction}

The world population is expected to rise to 9.7 billion by 2050, 2 billion more than the 7.7 billion of 2020 (United Nations, 2019). This growth, together with climate change and changing food consumption trends, is increasing the pressure to intensify agricultural production (Herzberg et al., 2019). However, impacts associated with agriculture intensification should be taken into account, such as excesses of nutrients like nitrogen $(\mathrm{N})$ and phosphorus $(\mathrm{P})$ that are released into water bodies or accumulate in soils and groundwater reservoirs.

To reduce the nutrient inputs, the European Union approved the Water Framework Directive (WFD, 2000) and the European Community Nitrates Directive (Council Directive (1991), 1991/676/EEC) specifically to reduce the nitrates in water bodies. Best Management Practices (BMPs) (CBPA, 2018) were proposed for the agricultural sector to reduce fertilizer use (organic and inorganic fertilizers). A number of different options can be taken, but the effect of these BMPs might not be immediately translated into improved conditions of the water bodies. According to Van Meter and Basu (2015), there are time lags between applying $\mathrm{N}$ fertilizers and the measurable effect in the river outlet, and these lags could vary from 1 year, decades, or centuries (Van Meter et al., 2017). The time lags could represent an important parcel of the current riverine nutrient exports of many watersheds.

To decrease the legacies of nutrients that remain in the watershed at least 1 year after their initial application (Van Meter et al., 2017), and understand their effect, different BMPs could be developed and evaluated. Appropriate methodologies should be used to identify the best possible alternatives. Decision making in managing agricultural systems is a process that normally involves multiple and conflicting criteria. Agricultural systems can only become sustainable if three factors are considered. These are usually referred to as "triple P": Planet (environmental), People (social), and Profit (economic) (Tzouramani et al., 2020). Multicriteria decision analysis (MCDA) is a coherent methodology that can consider multiple criteria simultaneously in the decision-making processes. Talukder (2016) favors using MCDA to assess agricultural sustainability saying "Hence, MCDA methods can be applied to agricultural sustainability assessment because the methods are structured and transparent, can break down complex problems, facilitate discussion and can produce a systematic and visual presentation of the perspectives of diverse stakeholders."

The use of MCDA in the sphere of agriculture has been an active research area with numerous papers published. The agricultural problems resolved by MCDA can be classed in groups. One of the most dynamic is related to the evaluation of land areas for specific crops. Mendas and Delali (2012) propose an MCDA approach to assess the most suitable land plots for growing durum wheat in the region of Mleta in Algeria considering criteria related to water availability, and soil properties such as drainage, permeability, $\mathrm{pH}$, electrical conductivity, active limestone, cation exchange capacity, soil useful depth and slope, and two criteria of proximity and availability of labor. The ELECTRE Tri method was considered the best resolution method to cope with this analysis. A GIS-MCDA model to evaluate land sustainability for cultivating a traditional grape variety in part of the province of Reggio Calabria in southern Italy is presented in Modica et al. (2014). They apply an analytic network process (ANP) to select the most appropriate locations for agricultural development. The process included criteria associated with land conditions such as land use, pedological factors, heat index, elevation, slope, and soil and surface aspect. Seyedmohammadi et al. (2018) use SAW, TOPSIS, and fuzzy TOPSIS to evaluate the capability and 
sustainability of lands for crop production in Ardabil Province of Iran. The analytical hierarchy process (AHP) and fuzzy AHP were specifically proposed to assign weights to criteria. Alganci et al. (2019) evaluate the land sustainability of vineyards in the Sarkoy region of Turkey by using spatial multicriteria analysis (SMCA) and conclude that the current vineyards are occupying land with low capability, and new alternative sites are proposed for vineyard plantations. More recently, Cogato et al. (2020) have also evaluated potential locations for vineyards in Italy and selected the best ones according to a mechanisability index built to determine the potential of mechanization for reducing production costs. Quinta-Nova and Ferreira (2020) analyze the suitability of emerging crops like pistachios and strawberries, and almond and walnut trees in the Beira Baixa region of Portugal by an MCDA method. They consider criteria including temperature, rainfall, hours of sunshine, humidity, biogeography, elevation, soil $\mathrm{pH}$, and soil organic matter. The results include the best location for each of the emerging crops proposed, and they were obtained using the AHP method.

The evaluation of alternative types of irrigation is another common area that makes use of MCDA. Latinopoulos (2009) proposes an MCDA method to analyze water pricing policies in irrigated agriculture in a rural area of Greece, considering socioeconomic and environmental objectives. Antunes et al. (2011) develop an MCDA approach combining a social multicriteria evaluation (SMCE) framework and AHP method to identify and compare the most suitable alternatives for improving irrigation practices in the Caia region of Portugal. The criteria proposed would assess the environmental, and social performance, economic efficiency, feasibility, and resilience of different irrigation technologies. Recently, Paul et al. (2020) have evaluated the possibility of using reclaimed water for irrigation in a water-scarce region of California by MCDA resolved with AHP. The criteria used were the crop type, climate conditions, water policies, irrigation status, and proximity to wastewater treatment plants.

Lastly, another important problem dealt with by MCDA is related to the sustainability of agricultural activities. Van Huylenbroeck and Damasco-Tagarino (1998) utilize an MCDA tool to choose the sustainable crops that could help vegetable farmers in Benguet, a province of the Philippines, by carrying out a conflict analysis model (CAM). Miranda (2001) proposes an MCDA tool to analyze the sustainability of four farming systems in Guíra Brazil, considering criteria related to ecological, social, and economic issues. Talukder et al. (2017) evaluate the sustainability of an agricultural system by applying the Elimination method of MCDA to a coastal farming area in Bangladesh. Fifty criteria from the categories productivity, stability, efficiency, durability, compatibility, and equity were proposed to evaluate the alternatives. Bartzas and Komnitsas (2020) consider an AHP to evaluate the sustainability of different agricultural management practices in Greece for growing Pistacia vera $L$. In this work, 13 criteria were used to take into consideration the most important pressures in the environmental, social, and economic spheres.

Comprehensive literature review works show the importance of MCDA to help decision making in agricultural management. At the turn of the millennium, Hayshi (2000) published a literature review of MCDA applied to the agricultural sector with 84 references. More recently, Berbel et al. (2018) have brought out a book that outlines emerging areas of MCDA applications in the agriculture sector. These are related to efficiency gains in the provision of public goods from agricultural systems; the development of rural areas by using MDCA to support decision makers in selecting locations for biofuel production plants that could increase farm income; the use of recycled water in agriculture areas with water scarcity problems; the assessment of farmers' readiness to implement precision agriculture practices and the integration of MCDA with other tools 
like life-cycle assessment analysis to resolve sustainability problems related to the agricultural sector. To give an idea of the dynamic in the applicability of MCDA, the recent work by Diaz-Balteiro et al. (2020) includes a literature review on the application of MCDA in the management of land and fisheries resources. They look at 628 papers, 323 of which are from the agricultural sector.

This literature review indicates that there is a vast body of research involving the use of MCDA and a limited body of research on the impacts of different management practices on vineyards with regard to environmental, social, and economic issues. This work proposes a multicriteria decision analysis method as a useful tool for defining sustainable agricultural solutions to overcome problems raised by soil legacies and the poor quality water bodies caused by the intensive use of nutrients. As far as can be ascertained from the literature review, this is a novel contribution. In fact, vineyard management, including $\mathrm{N}$ and $\mathrm{P}$ issues and the legacy nutrients aspect has never been dealt with by an MCDA approach.

Viniculture is one of the most important agricultural practices in Portugal and offers high economic and social benefits. However, it is also a culture that can raise important environmental impacts (Benedetto, 2013). Laca et al. (2021) argue that in the grape cultivation phase fertilizer use is the main contributor to the environmental impacts and they recommend the use of composted organic waste to reduce these impacts in a wine producing region in northern Spain.

Our approach proposes a set of criteria to evaluate different agricultural practices. They are related to environmental issues such as the nitrate accumulated in soils after 30 years of following the same agricultural practice, as well as nitrate and phosphate concentration in stream water and criteria related to socioeconomic issues like vine yields and costs. The soil and water assessment tool (SWAT), developed by the USDA Agricultural Research Service is used to compute criteria (Neitsch et al., 2011).

A range of methods is available to resolve the MCDA. Diaz-Balteiro et al. (2020) argue that the choice of the MCDA method "is made, in most cases, in a somewhat arbitrary way" and there are positive and negative arguments associated with each method. Talukder (2016) considers that, of the different MCDA resolution methods, some are more appropriate to agricultural problems, giving the reasons for his statements. These are the multi-attribute utility theory (MAUT), the preference ranking organization method for enrichment evaluation (PROMETHEE), and the elimination method. Cinelli et al., (2014) emphasized that PROMETHEE is one of the most widely used methods to resolve problems related to sustainability assessments as this is a powerful tool to support decision making. They also note that in PROMETHEE the compensation of very good or bad values associated with every single criterion are eliminated by using preference functions with threshold values to ensure the independence of each single criterion in the ranking of alternatives.

In this paper, the outranking method, PROMETHEE (Brans et al., 1986), is used to rank different alternative solutions of the problem at hand. This is based on computing the degree of dominance of one alternative over all the others by pairwise comparisons. This only requires having enough information to state that one alternative is at least as good as another (Brans et al., 1986). Other advantages of PROMETHEE are that it is user friendly and does not require that criteria are proportionate (criteria given by percentage) (Velasquez \& Hester, 2013). Supplementary information for decision makers will be provided by the evaluation of intervals of stability for weighting the criteria and by comparing the results from PROMETHEE with those given by a compensatory method (TOPSIS, Hwang et al. (1981)). 


\section{Methodology}

\subsection{Outline}

The methodology proposed for MCDA implementation is developed through three main steps according to Fig. 1.

The main components for accomplishing a multicriteria decision analysis are defined in the first step. This comprises establishing the alternatives for the solutions to be adopted, the criteria to evaluate the performance of the alternatives, and the set of weights representing the relative importance given to criteria. In the second step, all the alternatives are evaluated using the same criteria. This study considered two types of criteria: environmental and socioeconomic. They are evaluated by means of the SWAT model and information included in some databases. The implementation of these two steps is case dependent and it is fully explained in Chapter 3. Finally, the third step involves ranking the alternatives. PROMETHEE is used to rank the alternatives and the results are analyzed. The stability intervals concept is used and supplementary results, obtained by a compensatory method (TOPSIS), are compared and discussed to help decision makers in their choices (Chapter 4).

\subsection{PROMETHEE method}

The Visual PROMETHEE (Mareschal \& De Smet, 2009) method is used to rank the alternatives. This method is briefly explained. For a detailed analysis, see Brans and Vincke (1985) and Brans and Mareschal (2005). The multicriteria problem is structured with a number of alternatives $N A$ and a number of criteria $N C$. Expression (1) states the multicriteria problem considering all criteria to be minimized, but this problem structure can also include criteria to be maximized.

$$
\min \left\{C_{1}\left(a_{i}\right), C_{2}\left(a_{i}\right), \ldots, C_{k}\left(a_{i}\right), \ldots, C_{N C}\left(a_{i}\right) \mid a_{i} \in N A\right\}
$$

where $C_{k}\left(a_{i}\right)$ is the evaluation criterion $k$ for alternative $a_{i}$.
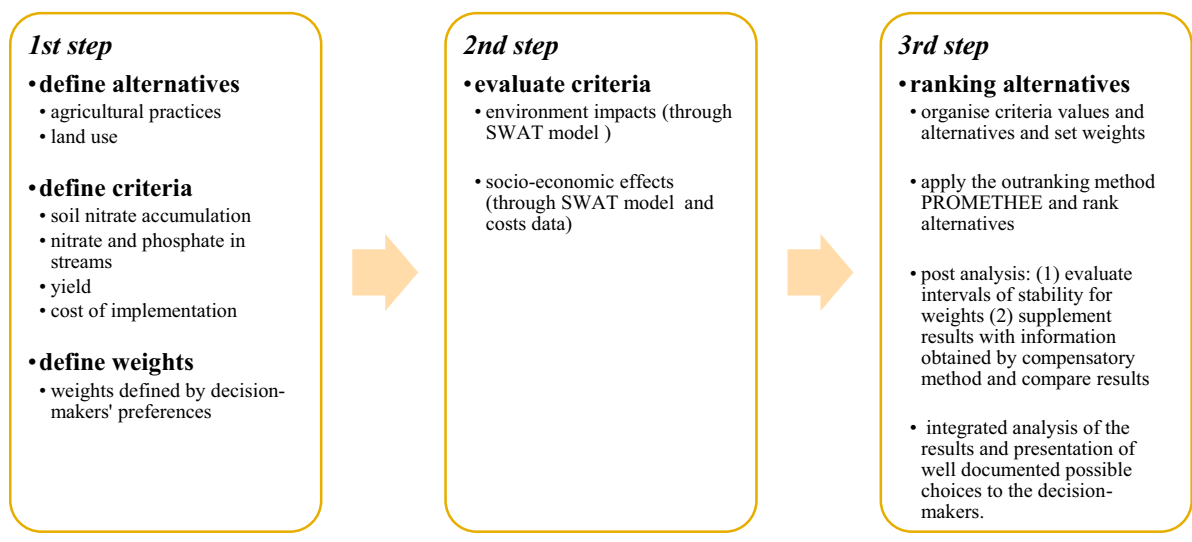

Fig. 1 Multicriteria decision analysis steps 
The set of $N A$ alternatives $\left\{a_{1}, a_{2}, \ldots, a_{i}, \ldots, a_{j}, \ldots, a_{N A}\right\}$ is evaluated for each of the $N C$ criteria $\left\{C_{1}(\cdot), C_{2}(\cdot), \ldots, C_{k}\left(a_{i}\right), \ldots, C_{N C}(\cdot)\right\}$. If there is an alternative that optimizes all criteria, it is easy to identify the best option. However, in most cases, there are conflicting goals and therefore there is no alternative that optimizes all criteria. In these cases, additional information is needed to find the best alternatives and suitable tools must be used, such as the PROMETHEE method, which is based on pairwise comparisons. These comparisons are established by the difference between the evaluation of two alternatives for a particular criterion and are computed by means of ( 2 and 3 ).

$$
\begin{gathered}
P_{k}\left(a_{i}, a_{j}\right)=F_{k}\left[-d_{k}\left(a_{i}, a_{j}\right)\right] \forall a_{i}, a_{j} \in N A \\
d_{k}\left(a_{i}, a_{j}\right)=C_{k}\left(a_{i}\right)-C_{k}\left(a_{j}\right)
\end{gathered}
$$

where $P_{k}\left(a_{i}, a_{j}\right)$ is the preference of alternative $a_{i}$ over $a_{j}$ for the evaluation criterion $k$ (given by a real number between 0 and 1$) ; F_{k}$ is the preference function and $d_{k}\left(a_{i}, a_{j}\right)$ is the difference between evaluations of alternatives $a_{i}$ and $a_{j}$ for criterion $k$.

The differences $d_{k}\left(a_{i}, a_{j}\right)$ computed in (3) are given by the difference between the criterion value $C_{k}$ for alternative $a_{i}$ and the criterion value $C_{k}$ for alternative $a_{j}$ and they are used to evaluate the preference of alternative $a_{i}$ over $a_{j}$ by means of preference functions $\left(F_{k}\right)$ that return real values between 0 and 1 . The preference functions assign preferences to the best alternatives or no preference if the difference is deemed negligible. For criteria to be minimized, the preference function is computed with the negative difference $-d_{k}\left(a_{i}, a_{j}\right)$. These preference functions define how comparisons between pairs of alternatives are translated into degrees of preference. Six different types of preference functions $\left(F_{k}\right)$ can be used in Visual PROMETHEE: Usual, U-shape; V-shape; Level; Linear and Gaussian. Some preference functions are recommended for qualitative criteria, such as Usual, U-shape and Level, and others for quantitative criteria (such as the criteria in this work), namely, V-shape, linear, and Gaussian. To choose the right preference function for each criterion, Visual PROMETHEE includes a preference function assistant (Mareschal, 2013) to suggest the use of a particular function. This assistant evaluates the distribution of the criteria values of the alternatives in terms of scale, minimum, maximum, range, average, standard deviation, and maximization/minimization type to arrive at the preference function that best fits all these measures. Applying this analysis to the current study leads to linear preference functions being suggested by the preference function assistant for the criteria used in this work. The next step is to aggregate the preferences computed in (2) in preference indices yielded by (4) and (5), considering all the criteria of the problem.

$$
\begin{aligned}
& \pi\left(a_{i}, a_{j}\right)=\sum_{k=1}^{N C} P_{k}\left(a_{i}, a_{j}\right) w_{k} \\
& \pi\left(a_{j}, a_{i}\right)=\sum_{k=1}^{N C} P_{k}\left(a_{j}, a_{i}\right) w_{k}
\end{aligned}
$$

where $\pi\left(a_{i}, a_{j}\right)$ is the preference of alternative $a_{i}$ over $a_{j}$ over all criteria; $w_{k}$ is the weight of criterion $k$ and $\pi\left(a_{j}, a_{i}\right)$ is the preference of alternative $a_{j}$ over $a_{i}$ over all criteria.

The preference index $\pi\left(a_{i}, a_{j}\right)$ evaluates for all criteria, how much $a_{i}$ is preferred to $a_{j}$, and preference index $\pi\left(a_{j}, a_{i}\right)$ computes how much $a_{j}$ is preferred to $a_{i}$. A value close to 0 for $\pi\left(a_{i}, a_{j}\right)$ is associated with a low preference of $a_{i}$ over $a_{j}$. A value near to 1 for $\pi\left(a_{i}, a_{j}\right)$ 
indicates a high preference of $a_{i}$ over $a_{j}$. These indices are used in PROMETHEE to compute two outranking values, the positive outranking value $\phi^{+}(a)$ in (6) and the negative outranking value $\phi^{-}(a)$ in (7).

$$
\begin{aligned}
\phi^{+}\left(a_{i}\right) & =\frac{1}{N A-1} \sum_{j \in N A, j \neq i} \pi\left(a_{i}, a_{j}\right) \\
\phi^{-}\left(a_{i}\right) & =\frac{1}{N A-1} \sum_{j \in N A, j \neq i} \pi\left(a_{j}, a_{i}\right)
\end{aligned}
$$

where $\phi^{+}\left(a_{i}\right)$ is the positive outranking value of alternative $a_{i}$ and $\phi^{-}\left(a_{i}\right)$ is the negative outranking value of alternative $a_{i}$.

The positive outranking evaluates the degree (the higher the better ranking) to which the alternative $a_{i}$ is outranking all the others. The negative outranking evaluates the degree (the lower the better ranking) to which the alternative $a_{\mathrm{i}}$ is outranked by all the others. Finally, the last step consists of computing the PROMETHEE complete outranking given by (8).

$$
\phi\left(a_{i}\right)=\phi^{+}\left(a_{i}\right)-\phi^{-}\left(a_{i}\right) .
$$

The comprehensive outranking value $\phi\left(a_{i}\right)$ of an alternative $a_{i}$ is determined by the difference between two indexes: the positive outranking value $\phi^{+}\left(a_{i}\right)$ (which translates the strengths of an alternative over all the others) and the negative outranking value $\phi^{-}\left(a_{i}\right)$ (which translates the weakness of an alternative relative to all the others). The higher the score of $\phi$, the better the alternative. For positive $\phi\left(a_{i}\right)>0$ alternative $a_{i}$ outranks all the alternatives more, in all criteria, and negative $\phi\left(a_{i}\right)<0$ alternative $a_{i}$ is outranked more by all the alternatives, in all criteria.

\section{Case study}

\subsection{Study area}

The São Lourenço basin is a $6.20 \mathrm{~km}^{2}$ agro-forested catchment in the Anadia municipality, Aveiro district, north-central Portugal (Fig. 2). As part of an important wine regionthe Bairrada-vineyards are the dominant land cover in São Lourenço, occupying $44 \%$ of the basin. The remaining area is mostly covered by maritime pine plantations $(27 \%)$ and annual rain-fed crops (18\%), namely maize, potato, and pasture, and to a lesser extent by eucalyptus plantations (3\%), permanent pastures (3\%) and mixed pine and eucalyptus forests (2\%) (Serpa et al., 2015, 2017). The climate of the basin is typically Mediterranean with oceanic influence (Köppen, Csb; Dinis et al., 2012), being characterized by mild and wet winters and warm and dry summers. The average annual rainfall and temperature in the study area are $925 \mathrm{~mm}$ and $15.7^{\circ} \mathrm{C}$ (SNIRH, 2014). Elevations range from 40 to $100 \mathrm{~m}$ a.s.l. and slopes are gentle (<5\%) (Serpa et al., 2015, 2017). Vineyard soils are predominantly Humic Cambisols, with high depth and high organic matter content (Serpa et al., 2015, 2017), but there are also vineyards being cultivated on Chromic Luvisols and Calcaric Cambisols (DGADR, 2013).

The São Lourenço experimental catchment was instrumented in 2012 within the scope of a nationally funded project_-VITAQUA (PTDC/AAC-AMB/112438/2009). The main goal of the VITAQUA project was to assess the potential impacts of climate change on 


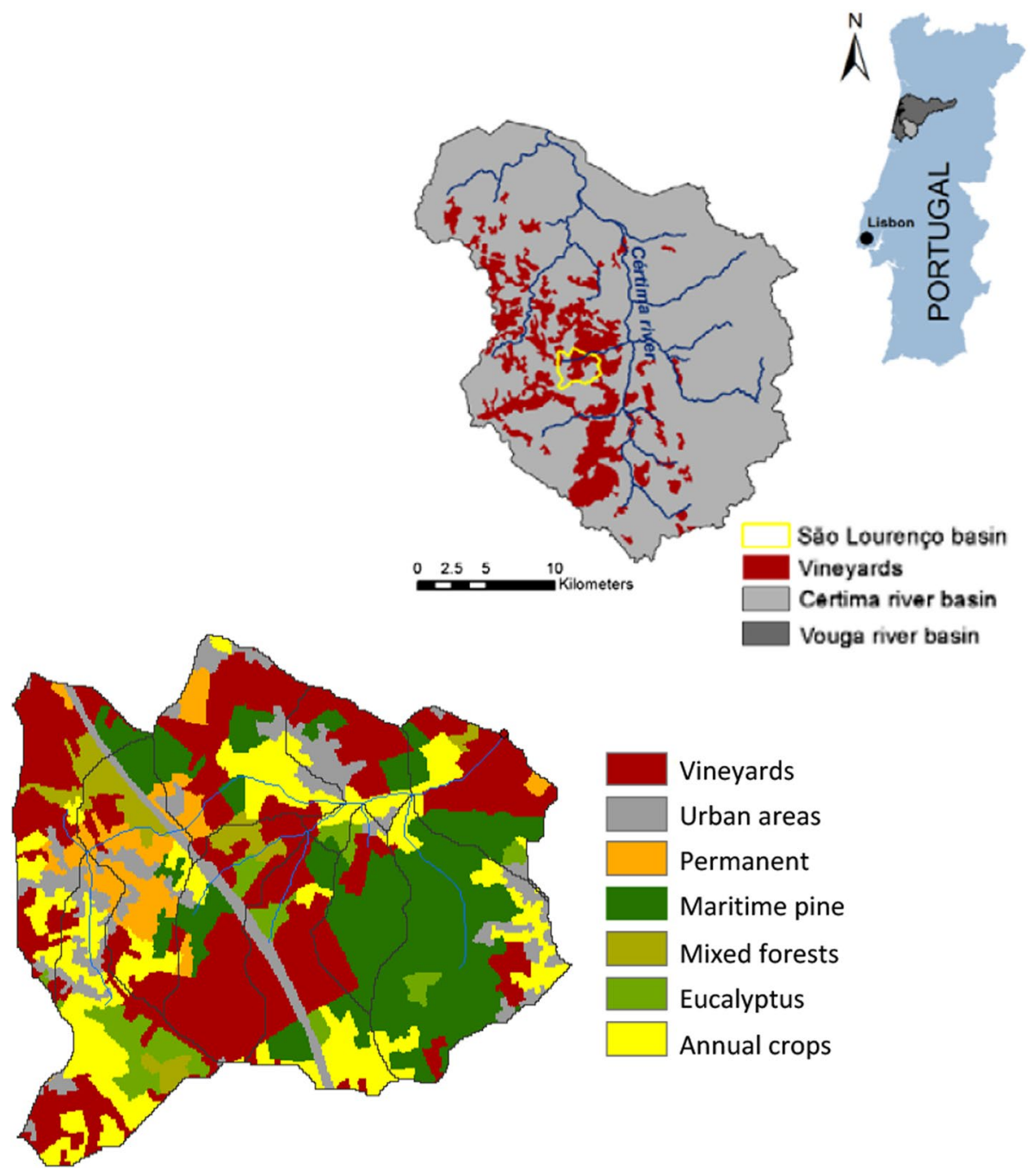

Fig. 2 The São Lourenço basin

aquatic ecosystems under intensive agricultural pollution (Serpa et al., 2015, 2017). A hydrometric station was installed at the catchment outlet, consisting of a water level sensor and an ISCO3700 automatic sampler, which was triggered by the water level sensor through a CR200 datalogger (Campbell Scientific () ) to collect samples for water quality analysis. Aside from the hydrometric station, 2 automatic (Pronamic Professional Rain Gauge with $0.2 \mathrm{~mm}$ resolution) and one totalizer rainfall gauges were also installed at the catchment. The reason for selecting this catchment was because it is dominated by vines, which is known to be a crop highly dependent on agrochemicals and therefore likely to pose a risk of contamination to both surface water and groundwater. Further research was carried out within and in the immediate surroundings of São Lourenço in the framework of the EU-funded MASCC (ARIMNet2, grant 618,127) and ISQAPER (EU Horizon 2020, Grant No. 635750) projects. This includes a study of the effects of different management 
practices on vineyard soils (Ferreira et al., 2018, 2020) and the effectiveness of biochar application on reducing overland flow and erosion in vineyards (Vieira et al., 2018).

Although no major environmental issues have been recognized in the São Lourenço basin, it is important to identify best management practices because often the impacts of intense fertilizer use in vineyard areas might not be immediately reflected in the status of water bodies (Van Meter et al., 2017). As an experimental catchment, São Lourenço is an interesting setting that offers the opportunity to discuss comparisons between different types of agricultural practices and give insights for future developments in larger areas where intensive vineyard cultivation is implemented. Additionally, the findings of this study could help us to better understand the issues at stake when the impact of integration with other cultures is foreseen in a decision-making process.

\subsection{SWAT model}

The SWAT model for the São Lourenço basin developed by Serpa et al., $(2015,2017)$ was used in the present work. This model has been calibrated and validated using data on streamflow, sediments, and nutrients ( $\mathrm{N}$ and $\mathrm{P}$ ) collected at plot and catchment scale (Ferreira et al., 2018; Serpa et al., 2015, 2017). For this work, the model was warmed up for a 10-year period to eliminate initial bias and then run for a period of 30 years (1971-2000; considered as a reference period), to study the legacy of agricultural practices in the basin. Information on agricultural and fertilization practices, i.e., application periods and rates, as well as other management operations, was obtained from the data published by the Portuguese Ministry of Agriculture (INIA-LQARS, 2000).

The doses recommended by the fertilizers' manufacturers for the different crops were also considered when defining application rates (see Serpa et al., 2017).

In the SWAT model, nitrogen $(\mathrm{N})$ is partitioned into three pools of organic forms (fresh, stable, and active $\mathrm{N}$ ) and two pools of inorganic $\mathrm{N}$ forms (ammonium and nitrates). Nitrate can be added to the soil by inorganic fertilizers, but it is also a result of soil organic matter mineralization and nitrification processes. The main removal pathways of nitrate in soils are via plant uptake, denitrification, and leaching. Because nitrate retention in soils is minimal, nitrate is very susceptible to leaching, being transported out of the soils by surface runoff and lateral flow (Neitsch et al., 2011).

Phosphorus (P) in the soil is partitioned into six pools in the SWAT model: three inorganics (fresh, active, and stable), and three organics (fresh, active, and stable). Phosphorus can be added to the soil by fertilizer, manure, or residue application, and is removed mainly via plant uptake, surface runoff, and erosion (Neitsch et al., 2011). In the SWAT model, surface runoff is the principal pathway of $\mathrm{P}$ export from the basin. Nutrient loadings in the model are routed by streamflow and distributed to the watershed outlet. Once in stream, processes adopted from the QUAL2E water quality model govern nutrient transformations (Neitsch et al., 2011).

\subsection{Alternatives}

\subsubsection{Vineyard practices}

Winegrowers in São Lourenço, as in most of the Bairrada wine region, usually follow conventional management practices, but in the last decades an increasing number of farmers have adopted integrated production practices (Ferreira et al., 2020). Conventional practices 
in the Bairrada region involve intensive tillage ( 3 to 5 times per year) with heavy machinery (typically a wheeled tractor with a chisel penetrating $20 \mathrm{~cm}$ into the soil) and intense use of fertilizers ( 2 foliar fertilizations per year and mineral fertilization of the soil once every 2 years) and pesticides (Ferreira et al., 2020). Integrated management, on the other hand, involves reduced ( 2 times per year) and shallower chiseling $(15 \mathrm{~cm}$ depth) to maintain a partial soil cover, regulated fertilization rates ( 2 foliar and manure fertilizations per year) and selective application of pesticides, typically according to the guidelines specified and updated whenever needed by regional authorities. Given the increasing public awareness of product safety, some farmers in the Bairrada region have adopted production systems based on biodynamic principles (Ferreira et al., 2020). Biodynamic management relies mostly on manual practices, so tillage is only performed sporadically. In this type of cultivation system, phytoproducts are typically made from medicinal herbs and/or organic residues (e.g., cow manure), being applied once a year to enhance the plant vegetative and reproductive growth as well as to increase resistance to pests and diseases (Ferreira et al., 2020).

Conventional vineyards are likely to have a higher environmental impact than integrated production and, especially, biodynamic production. This is largely due to the higher mobilization of soils as well as the higher fertilization rates, and frequency of use under conventional practices, which aim to maximize vine production.

\subsubsection{Land use changes}

According to the European and Portuguese land use trends, a large decrease in agricultural lands for food production is expected in the future (Serpa et al., 2015, 2017). In São Lourenço, traditional agricultural crops such as small vineyards, potatoes, and pastures are expected to be replaced primarily by maize (for biofuel production) and by commercial forests (Serpa et al., 2015, 2017). In the present work, an alternative land use change was defined, focusing on economic development. In this alternative, the vineyards area decreases in the basin since small vineyards are partially replaced by maize, for biofuel production, and by eucalyptus plantations, as this is considered a valuable species for the paper pulp industry.

Regarding land use changes, replacing vineyards with maize and eucalyptus plantations is likely to lead to an increase in nitrogen forms in soils because maize is a crop that makes more demands on $\mathrm{N}$ fertilization than vines (INIA-LQARS, 2000). The replacement of vineyards by eucalyptus plantations, on the other hand, is likely to have had little influence on these findings for two reasons: i) only a small fraction of vineyard area was converted to eucalypts; ii) eucalyptus plantations are only fertilized with $\mathrm{N}$ when trees are planted. The higher availability of nitrate in soils is expected to lead to an increase in its concentrations in stream water since this $\mathrm{N}$ form is very susceptible to leaching, and is transported both by surface runoff and lateral flow (Neitsch et al., 2011). Phosphorus concentrations in stream water are expected to be practically unaffected by vineyard conversion because maize $\mathrm{P}$ requirements are not substantially different from those of vineyards.

Given these vineyard management practices as a reference, three alternatives are proposed based on the integrated, conventional, and biodynamic practices previously detailed. Another alternative was also considered, using integrated vineyard management practices as reference, which consisted of altering the land use by replacing the potato and pasture areas with an extra $98 \%$ of maize cultivation, and increasing the eucalyptus plantations by $190 \%$, while decreasing the vineyard area by $16 \%$. 


\subsection{Criteria definition and evaluation}

The São Lourenço basin is partially located over the Bairrada karst, a system that has two main aquifers originating from Jurassic limestone (Almeida et al., 1998). As a result of the high infiltration rates and fast water flow through the karstic structures, the aquifers are extremely vulnerable to pollution and have a very low ability for self-purification (Almeida et al., 1998). As nitrates are highly vulnerable to leaching (Neitsch et al., 2011), they can be used as a proxy for evaluating the potential impacts of agriculture fertilization on groundwater quality in the São Lourenço basin. Their accumulation in soils due to agricultural practices is an important environmental criterion to be evaluated.

The impacts of agricultural practices on stream water quality can be evaluated from nitrate and phosphate water concentrations since inorganic $\mathrm{N}$ forms are readily available to primary producers and therefore likely to cause eutrophication of water bodies. There are established threshold quality levels for nitrates and phosphates for multipurpose surface waters because of the relevance of these criteria when evaluating the status of water bodies.

As Portugal is the fourth largest wine producer in Europe (Ferreira et al., 2018), vine yield is a criterion of unquestionable relevance for this work since it directly reflects into the economy of the region. In Portugal, vine production has been reported to vary between 5 and 30 tons/ha depending on edaphoclimatic conditions, cultivation techniques, and the purpose of the production, i.e., grape or wine production (ADP, 2021).

As an additional criterion, the cost of each alternative described above is also considered. The cost of maintaining the vineyard over the year is related to tillage, fertilization, herbicide, phytosanitary treatments and weed cuts (for the biodynamic alternative), pruning, interventions in the vegetation growth phase, and the grape harvesting. The cost breakdown is based on the works of Garrido and Mota (2011) and Rúbio (2013).

For this work, SWAT was used to simulate the reactions, accumulation, and transportation processes of nutrients as well as to estimate crop yields. Details regarding the model application, i.e., calibration, validation, and performance evaluation, to the São Lourenço basin can be found in Serpa et al. (2017). The model was used to simulate the four alternatives described in the previous section. From the SWAT outputs, those related to $\mathrm{NO}_{3}-\mathrm{N}$ legacies in soils after 30 years of using the same agricultural practice $(\mathrm{kg} / \mathrm{ha})$, as well as the average values of $\mathrm{NO}_{3}-\mathrm{N}, \mathrm{PO}_{4}-\mathrm{P}$ stream concentrations $(\mathrm{mg} / \mathrm{L})$, and vine yield $(\mathrm{t} / \mathrm{ha})$ during the same period were selected to compare the different alternatives. The average annual cost value was also determined.

\subsection{Weights}

An MCDA analysis entails defining a set of weights expressing the relative importance given to the criteria. Weights, in a real-world case study, would embody the opinions of decision makers. Although this is an academic study (still considering many of the features of practical problems addressed in this field), the perspectives found in the literature to deal with decision making in the agricultural sector are used here to address this issue. Therefore, a sensitivity analysis of the impacts of the weights has to be promoted. To this end, four weight sets (WSs) are proposed in Table 1. WS1 and WS2 assign more importance to the environmental group of criteria allotting them a value of 0.8 (and 0.2 to the socioeconomic criteria). WS1 privileges the $\mathrm{NO}_{3}-\mathrm{N}$ component (soil $\mathrm{NO}_{3}-\mathrm{N}$ and stream $\mathrm{NO}_{3}-\mathrm{N}$, with 0.35 for each one) and WS2 emphasizes $\mathrm{PO}_{4}-\mathrm{P}(0.7)$. For the socioeconomic criteria 
Table 1 Weight sets (WSs) assigned to criteria

\begin{tabular}{llllll}
\hline Weights & $\mathrm{Soil} \mathrm{NO}_{3}-\mathrm{N}$ & Stream $\mathrm{NO}_{3}-\mathrm{N}$ & Stream $\mathrm{PO}_{4}-\mathrm{P}$ & Vine yield & Costs \\
\hline WS1 & 0.35 & 0.35 & 0.1 & 0.1 & 0.1 \\
WS2 & 0.05 & 0.05 & 0.7 & 0.1 & 0.1 \\
WS3 & 0.067 & 0.067 & 0.067 & 0.5 & 0.3 \\
WS4 & 0.067 & 0.067 & 0.067 & 0.3 & 0.5 \\
\hline
\end{tabular}

(vine yield and costs criteria), weights of 0.1 were assigned in these two weight sets. In WS3 and WS4, the importance of environmental criteria is reduced (soil $\mathrm{NO}_{3}-\mathrm{N}$, stream $\mathrm{NO}_{3}-\mathrm{N}$, and stream $\mathrm{PO}_{4}-\mathrm{P}$ ) to an overall value of 0.2 (equally distributed among these criteria, each with the value of 0.067). Then, in WS3 and WS4 a total value of 0.8 is assigned to the socioeconomic criteria. In WS3, the highest importance is given to vine yield (0.5), and in WS4, the cost criterion has the highest weight (0.5).

\section{Results and discussion}

\subsection{Evaluation matrix}

The alternatives presented in Sect. 3.3 are synthesized and depicted in the first and second columns of Table 2 ("Integrated," "Conventional," and "Biodynamic" agricultural practices and a possible new one, "Land use") and are evaluated against all the criteria defined in Sect. 3.4. The SWAT model was used to evaluate environmental criteria (soil $\mathrm{NO}_{3}-\mathrm{N}$ accumulation, $\mathrm{NO}_{3}-\mathrm{N}$ and $\mathrm{PO}_{4}-\mathrm{P}$ concentrations in the stream) and the socioeconomic criterion (vine yield). The other socioeconomic criterion, costs, was picked from references already mentioned in Sect. 3.4. The results are shown in columns 3-7 of Table 2.

From Table 2, the most expensive alternative is conventional and the least costly is biodynamic as this alternative only considers one manure fertilization per year and there is no tillage, which also decreases costs. As land use and integrated consider the same vineyard practices, the cost per hectare of these alternatives is very similar and roughly $12 \%$ less than that of conventional and $8 \%$ higher than the cost of biodynamic. Conventional is the most expensive alternative, but also has the highest vine yield (52.6\% higher than biodynamic and $6.6 \%$ higher than integrated). The yield of this alternative is associated with the application of more fertilization than happens with the other alternatives. Biodynamic has the lowest vine yield, but this is also the alternative with the best criteria values of soil $\mathrm{NO}_{3}-\mathrm{N}$, stream $\mathrm{NO}_{3}-\mathrm{N}$, and stream $\mathrm{PO}_{4}-\mathrm{P}$. As expected, the worst option for environmental criteria is conventional, showing a $73.89 \%$ increase in $\mathrm{NO}_{3}-\mathrm{N}$ accumulation and an average increase in stream water concentrations of $\mathrm{NO}_{3}-\mathrm{N}$ and $\mathrm{PO}_{4}-\mathrm{P}$ of $152.74 \%$ and $257.14 \%$, respectively, relative to the biodynamic alternative. Conventional also shows an increase of $42.9 \%, 99.46 \%$, and $92.31 \%$ for the same parameters with regard to the integrated alternative. As expected, the land use alternative (Sect. 3.3) gave rise to a small increase in environmental impacts with regard to $\mathrm{NO}_{3}-\mathrm{N}$ accumulation in soil and $\mathrm{NO}_{3}-\mathrm{N}$ stream water concentration. Phosphorous in stream water is practically unaffected. A decrease in the vine yield was noticed.

It is worth mentioning that an alternative where the whole São Lourenço basin was used just for vineyard development would lead to higher values of phosphorus components than 


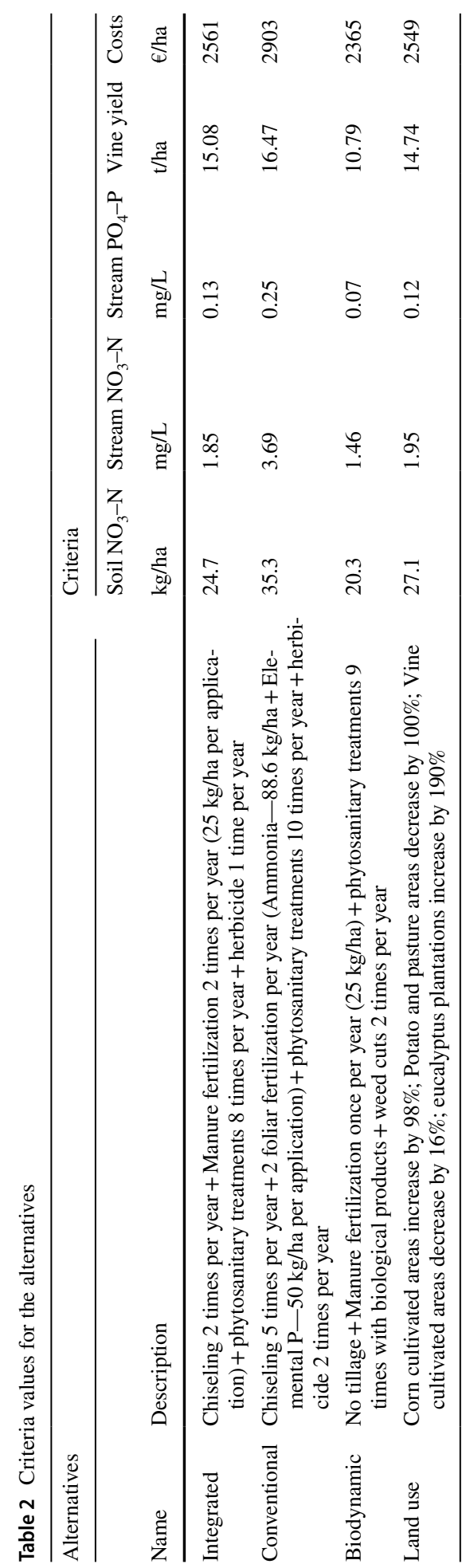


the legally acceptable limits for the conventional alternative practice (in stream the limit is $0.21 \mathrm{mg} \mathrm{L}^{-1}$ and the value obtained was $1.45 \mathrm{mg} \mathrm{L}^{-1}$ ). Even the integrated alternative would drive the $\mathrm{NO}_{3}-\mathrm{N}$ in the soil to an increase of $32 \%$ and in the stream to an increase of 43.2\%. As mentioned in Sect. 3.1, São Lourenço is an experimental setting; however, based on all the information gathered up to now, it is clear that scaling-up the intensive use of land areas to vineyard cultivation should be carefully planned and the conclusions of this study can give insights to future work.

The PROMETHEE method is used to rank the alternatives. Weights were already defined in Sect. 3.5, for use with this method, to express the relative importance assigned to each criterion. A sensitivity analysis is also carried out to ascertain the effects of the four weight sets proposed.

\subsection{PROMETHEE results}

The Visual PROMETHEE program (Mareschal, 2013) is used to rank the alternatives for the four weight sets, according to the Phi value $(\phi)$ (using PROMETHEE II), and the results are presented in Table 3 . The positive Phi $+(\phi+)$ and negative Phi- $(\phi-)$ outranking values are also included (using PROMETHEE I).

The results in Table 3 show that if the highest weight is attributed to soil $\mathrm{NO}_{3}-\mathrm{N}$ legacy and stream $\mathrm{NO}_{3}-\mathrm{N}$ concentration (WS1) or to the stream $\mathrm{PO}_{4}-\mathrm{P}$ concentration criteria (WS2), the best option is the biodynamic and the worst is the conventional. The biodynamic alternative combines the best Phi+ and Phi- values, for both WSs. The opposite can be said for the conventional option with the worst values for Phi+and Phi-. These partial outranking Phi+ and Phi- values give additional confidence to the rankings of the alternatives. For WS1 and WS2, the best option is biodynamic because this alternative guarantees the minimum concentrations of nitrates and phosphates in the São Lourenço basin. Conventional should not be an option if the main objective is to improve the soil and water

Table 3 Rankings by PROMETHEE

\begin{tabular}{lllrll}
\hline & Rank & Alternative & Phi & Phi+ & Phi- \\
\hline WS1 & 1 & Biodynamic & 0.4238 & 0.5147 & 0.0909 \\
& 2 & Integrated & 0.2198 & 0.3269 & 0.1071 \\
& 3 & Land use & 0.1058 & 0.2699 & 0.1641 \\
& 4 & Conventional & -0.7493 & 0.0551 & 0.8045 \\
WS2 & 1 & Biodynamic & 0.4323 & 0.5232 & 0.0909 \\
& 2 & Land use & 0.1754 & 0.2995 & 0.1241 \\
& 3 & Integrated & 0.1358 & 0.2797 & 0.1439 \\
& 4 & Conventional & -0.7435 & 0.0551 & 0.7986 \\
WS3 & 1 & Integrated & 0.1848 & 0.3040 & 0.1192 \\
& 2 & Land use & 0.1319 & 0.2776 & 0.1457 \\
& 3 & Biodynamic & -0.1531 & 0.3011 & 0.4541 \\
& 4 & Conventional & -0.1637 & 0.2754 & 0.4391 \\
WS4 & 1 & Integrated & 0.1601 & 0.2916 & 0.1316 \\
& 2 & Biodynamic & 0.1532 & 0.4257 & 0.2725 \\
& 3 & Land use & 0.1335 & 0.2783 & 0.1449 \\
& 4 & Conventional & -0.4468 & 0.1652 & 0.6120 \\
\hline \multirow{6}{*}{ W } & & & & &
\end{tabular}


quality by reducing the nutrient loads. For WS1, the integrated option comes in second place and in WS2, land use occupies the second position. Land use being second in WS2 is related to the better value of the stream $\mathrm{PO}_{4}-\mathrm{P}$ criterion of this option (0.12), compared with the integrated alternative (0.13), and in WS2, the highest weight is attributed to stream $\mathrm{PO}_{4}-\mathrm{P}$. The best ranked for WS3 and WS4 is the integrated alternative, and conventional is last. In WS3, the highest weight is attributed to vine yield. The integrated option presents the second-best yield (15.18 t/ha), being lower than the conventional yield (16.47 t/ ha). However, the integrated practice alternative is better in all other criteria compared to conventional alternative. In WS4, the highest weight is attributed to costs. Biodynamic has the best cost but comes in second position. This is because biodynamic has the lowest vine yield (10.79 t/ha) of all alternatives, which tends to decrease its ranking if some importance is given to the vine yield criterion. In WS4, the weight value of 0.3 value is attributed to vine yield.

\subsection{Sensitivity analysis of weights attributed to criteria}

The results of multicriteria decision analysis are influenced by the weights attributed to criteria. Defining these weights is always a challenging process. The Visual PROMETHEE software used in this work is able to compute stability intervals to understand how an alternative ranking is sensitive to the weights (Mareschal, 2013). The stability interval concept is defined to measure the amplitude of variation of a weight assigned to a criterion, while keeping the same weights for the other criteria, without influencing the ranking of the alternatives. This indicates how sensitive a ranking order can be to a criterion weight change.

Table 4 includes the minimum and maximum weights that can be attributed to criteria without altering the ranking of alternatives for the four weight sets. The difference between these maximum and minimum weights shows to what extent the weights of a criterion can be altered without changing the position of alternatives. The larger the stability interval, the less sensitive the ranking.

Table 4 shows distinct situations. In WS1, the large stability ranges mean that the ranking of alternatives will be the same for a large range of weights. The stability interval for the weights of the soil $\mathrm{NO}_{3}-\mathrm{N}$ and stream $\mathrm{NO}_{3}-\mathrm{N}$ includes the largest possible range $(=1)$. This means that the variation of one of these criteria weights will not impact rankings. The vine yield weights have narrow stability intervals in WS1 as well as in other WSs, going from 0.2782 in WS2 to 0.0172 in WS4. WS2 and WS3 show closer stability intervals between criteria and WS4 present the narrowest stability intervals. A small change in the weights of this criterion in such a circumstance will alter the ranking position of alternatives. Therefore, for a real-world problem, stability intervals are an issue for decision makers that should drive them to a thorough analysis of the different solutions involved.

\subsection{Supplementary analysis with TOPSIS}

In the two weight sets WS3 and WS4, the partial outranking values Phi+ and Phi- are not following the ranking positions of alternatives given by the complete outranking value Phi (Table 3). Land use includes the third best Phi+ value (0.2776) in WS3 and is in second position and the biodynamic alternative has the third worst negative Phi- value $(0.2725)$ in WS4, but is in second position. A further analysis can be made to assess situations in which the partial outranking order is different from the order provided by Phi. 


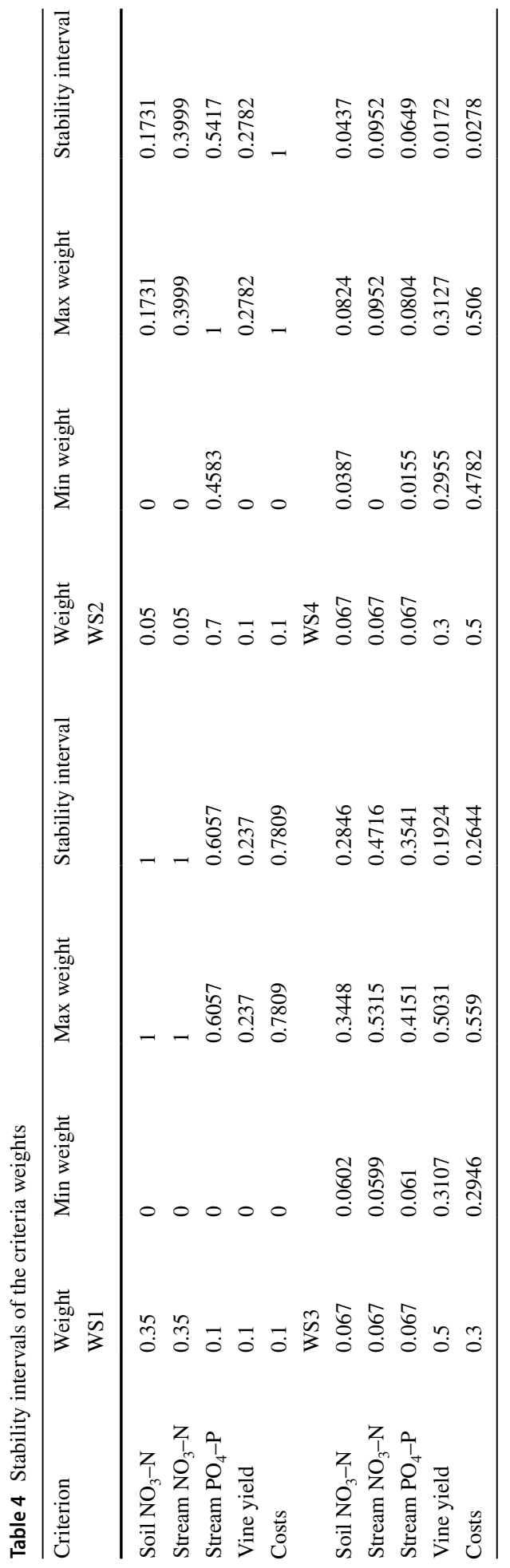


As already stated, Phi is given by the sum of the positive Phi+ with the negative Phiand the single value Phi computed for each alternative makes it possible to compare all alternatives. According to Brans and Mareschal, (2005), the ranking defined by Phi could be controversial if the partial positive Phi+and negative Phi- values fall in non-comparable situations. An example of this is the case of biodynamic in WS4. This alternative includes the best value Phi+ (0.4257) outranking value but includes the second worst value for Phi$(0.2725)$. In this case, the information provided by the partial outranking can raise some doubts and a supplementary analysis could bring new insights to the decision makers. In fact, these situations occur in rankings for WS3 and WS4 (Table 3).

A supplementary analysis will be performed by a different MCDA method (TOPSIS), belonging to the family of compensatory methods, to provide further information about these non-comparable situations in terms of the partial outrankings. The TOPSIS method was proposed by Hwang et al. (1981) and is a widely used method for resolving MCDA. Çelikbilek and Tüysüz (2020) argue that TOPSIS is a simple and easy to use method that can be applied to complex problems. TOPSIS is a stepwise procedure with 6 steps. The first step is used to normalize the decision matrix. The second step consists of multiplying the values in the normalized decision matrix by the criteria weights. In the third step, the positive ideal and negative ideal solutions that contain the best values and the worst values, respectively, for all criteria are obtained from the weighted normalized matrix. In the fourth step, the distance of each alternative to the ideal and anti-ideal solutions is determined. In the fifth step, the relative closeness coefficients $\mathrm{Clc}$ are computed using the distance measures of the fourth step and finally, in the sixth step, alternatives are ranked according to the $C l c$ value in descending order. The best options are those with coefficients close to 1 . The TOPSIS method was applied to the criteria values of Table 2 and for WS3 and WS4. The results are in Table 5.

The rankings obtained by TOPSIS for WS3 and WS4 are different from those of PROMETHEE. These methods have different structures. PROMETHEE evaluates each alternative by pairwise comparisons over the other alternatives and TOPSIS uses a concept to rank alternatives based on the distance of each alternative to positive ideal and negative ideal solutions.

For WS3, the biodynamic alternative is in the last position in TOPSIS and it is in the penultimate position in PROMETHEE. This can give further confidence for decision making that biodynamic is not a good option when a high weight is assigned to the yield criterion. In PROMETHEE this alternative has the worst value for Phi- $(0.4541)$ due to the worst yield criterion and is also balanced with a high value for the positive Phi+ (0.3011) associated with the best value for cost and minimum concentrations of nitrates and phosphates criteria, which tend to improve its rank position. These high values for Phi+ and Phi- are usually associated with alternatives with extreme criteria values. PROMETHEE evaluates each alternative by pairwise comparisons as demonstrated

Table 5 Rankings by TOPSIS

\begin{tabular}{llllll}
\hline Rank & WS3 & & & WS4 \\
\cline { 2 - 3 } \cline { 5 - 6 } & Alternative & $C l c$ & & Alternative & Clc \\
\hline 1 & Integrated & 0.732 & & Integrated & 0.716 \\
2 & Land use & 0.696 & & Land use & 0.693 \\
3 & Conventional & 0.578 & & Biodynamic & 0.507 \\
4 & Biodynamic & 0.422 & & Conventional & 0.493 \\
\hline
\end{tabular}


in Sect. 2.1 and this tends to decrease the influence of these extreme values for criteria. In TOPSIS, the extreme worst values for criteria increase the distances to a positive ideal solution, and that lowers its ranking. In fact, the integrated and land use alternatives have the same ranking position in PROMETHEE and TOPSIS for WS3 and these are alternatives without extreme values for criteria.

For WS4, the biodynamic is the third option for TOPSIS and it is in the second position for PROMETHEE (Table 3). In WS4, the highest weight is attributed to costs (0.5), but some importance is also attributed to yield criteria (0.3). TOPSIS reduces the ranking of the biodynamic due to value of yield of this alternative, which increases the distance to positive ideal and decreases the distance to the negative ideal solution. There is not enough compensation for being maintained in the position obtained in PROMETHEE due to the good value of Phi+ (mainly because, in this case, this alternative has the best value of costs). In fact, in terms of the PROMETHEE partial rankings, this alternative comes in third position (the same as TOPSIS) for the negative Phi- partial ranking and in the first position for positive Phi+ partial ranking. For WS4, the same best (integrated) and the same worst (conventional) alternatives are determined by TOPSIS and PROMETHEE. Integrated is a well-balanced alternative without extreme values for criteria and both methods assign the same position to this alternative; this is also the best option according to negative Phi- partial ranking of PROMETHEE. Conventional is the alternative with the worst value for cost criterion and in TOPSIS this tends to increase the distance to a positive ideal solution. This alternative is also the worst option in terms of Phi+ and Phi- partial rankings in PROMETHEE.

The rankings of alternatives for WS4 of TOPSIS are equal to the rankings provided by PROMETHEE for WS3. In these weight sets, the same overall value of 0.8 is assigned to the socioeconomic criteria but in WS3 the highest importance is attributed to vine yield and in WS4 to the cost criterion. The TOPSIS ranking is more negatively influenced by the extreme value of the biodynamic alternative for the yield criterion than PROMETHEE, and therefore giving a lower weight to the yield criterion in WS4 relative to WS3 can be translated in the same ranking of the TOPSIS analysis relative to PROMETHEE, which is less influenced by the yield criterion value.

TOPSIS has also been applied to WS1 and WS2 and, as expected, the rankings found by PROMETHEE were maintained. In these weight sets, the partial outranking Phi+ and Phi- of PROMETHEE give the same rankings of the alternatives, too (Table 3), and these are the weights with the larger stability intervals (Table 4). Even using methods of different families, the rankings of alternatives for WS1 and WS2 remain unchanged. It is clear that the conventional alternative is the worst one, even when the highest weights are assigned to the criteria where it offers the best performance. It is quite an unbalanced alternative. Overall results show that biodynamic and integrated were the alternatives that reached the first position four times (biodynamic achieved the first position four times when the highest weights were assigned to environmental criteria, and integrated did so when the highest weights were assigned to socioeconomic criteria). However, the integrated alternative has never been placed in the last position, as happened with biodynamic for WS3 for TOPSIS ranking. Additionally, it has only been ranked in the third position once (biodynamic occupied this position twice). Biodynamic should be carefully considered as an option if environmental issues are of crucial importance. Where socioeconomic aspects prevail, integrated vineyard practices could be a good option for the São Lourenço basin. However, it can be stated, after the previous analysis, that the integrated alternative is the most well-balanced, considering all the criteria and all the weights. Integrated and land use sometimes swap their second and third positions, but 
land use never ends up in a first position. This means that land use changes should be carefully evaluated for real-world problems.

\section{Conclusions}

A great deal of concern is aroused by the intensification of agricultural production to respond to the needs of an increasing world population that is expected to reach 9.7 billion by 2050. Additionally, changing food consumption trends in some parts of the world and the impact of climate change are creating new challenges. It is clear that problems of soil nutrient legacies and poor quality of water bodies are provoked by unsuitable agricultural practices. Therefore, sustainable issues should be at the heart of decision-making options when it comes to deciding about the most appropriate agricultural practices and land use. Decisions in this area are manifold. In fact, the three dimensions of sustainability (environmental, social, and economic) are present and there are various stakeholders expressing a variety of perspectives. This is why a multicriteria decision analysis (MCDA), an organized and coherent way for simultaneously embracing all the issues at stake, has been developed in this paper to deal with management practices in vineyards. To the best of the authors' knowledge, vineyard management, including $\mathrm{N}$ and $\mathrm{P}$ issues and the legacy nutrients aspect, has never been dealt with by an MCDA approach integrated with other sustainability components.

The most important takeaways from this work are related to the findings about the different agricultural practices (conventional, biodynamic, integrated, and land use change) evaluated against sustainability criteria (to this end, the important role of the already calibrated SWAT model should be flagged here), the need for a sensitivity analysis of the results for different sets of weights, and the wealth of information gathered if results of different families of MCDA methods are compared.

It is clear that the "Conventional" type of agriculture should not be an option if the concerns are about reducing the nutrient loads. Additionally, this is in the last ranking position in seven out of eight MCDA attempts using different methods and weight sets. But, in contrast, "Biodynamic" should be thoughtfully assessed as a choice if environmental issues are critically important in the decision-making process. However, biodynamic presents an interesting performance, even when integrating all components of sustainability and the socioeconomic aspects prevail. The most well-balanced alternative is the integrated, with good performances for both types of criteria. Its environmental features are between biodynamic and conventional, showing the second-best yield and costs (costs of integrated and land use are quite similar). Land use performs quite similarly to integrated. In fact, in this case the integrated agricultural practice is used, and only the size of land plots assigned to different cultures was changed. The São Lourenço basin is an experimental catchment, therefore scaling-up land use changes in future real-world implementations should be the subject of an additional assessment.

Even when weights are not definitely established, or some hesitations are expressed, MCDA methods include the means for giving insights to decision makers. In fact, results can also be analyzed in terms of stability intervals to understand how the alternative ranking is sensitive to the weights. In the present study, it has been concluded that the most stable ranking appears when environmental criteria are the most relevant, and the criterion that presents the narrow stability interval, for all sets of weights, is the vine yield. So, in real-world situations this issue must be well thought-through because this means that a 
slight change in the weights assigned to this criterion can modify the overall ranking of alternatives.

The results provided by the PROMETHEE method, which belong to the family of noncompensatory methods, are supplemented by TOPSIS results, a compensatory method, and therefore they offer further perceptions for the decision-making process. In fact, it is clear that this type of analysis is very helpful when the alternatives exhibit extreme values for the different types of criteria considered.

Acknowledgements The authors would like to acknowledge funding from the WaterJPI-WaterWorks2015 ERA-NET Cofund 2016 Joint Call, Fundação para a Ciência e a Tecnologia (FCT), WATERJPI/005/2016; 3599-PPCDT. This study was further supported by the VITAQUA project (PTDC/AAC-AMB/112438/2009) funded by the European Regional Development Fund (through the Competitiveness Factors Operational Programme-COMPETE), the European Social Fund (through Human Potential Operational Programme) and the Portuguese Republic (through FCT). The authors would also like to acknowledge the financial support of CESAM (UIDP/50017/2020 + UIDB/50017/2020) and of CEMMPRE (Project UID/EMS/00285/2020) by FCT/MCTES and, through national funds. DS was funded by national funds (OE) through FCT, under the framework contract foreseen in numbers 4, 5, and 6 of Article 23, of the Decree-Law 57/2016, of August 29, amended by Law 57/2017, of July 19. Thanks are also due to FCT for the IF research Grant of JK (IF/01465/2015).

Authors' contributions MC contributed to conceptualization, methodology, supervision, validation, and writing - review and editing. DS contributed to data curation, software, resources, validation, and writingoriginal draft preparation. JM contributed to data curation, software, validation, and writing —original draft preparation. JK contributed to resources, validation, and reviewing. NA contributed to resources, validation, and reviewing.

Funding This study was funded by WaterJPI-WaterWorks2015 ERA-NET Cofund 2016 Joint Call, Fundação para a Ciência e a Tecnologia, WATERJPI/005/2016; 3599-PPCDT and Fundação para a Ciência e a Tecnologia, CESAM (UIDP/50017/2020+UIDB/50017/2020).

Data availability All data generated or analyzed during this study are included in this published article [and its supplementary information files].

\section{Declarations}

Conflict of interest The authors declare that they have no conflict of interest.

Open Access This article is licensed under a Creative Commons Attribution 4.0 International License, which permits use, sharing, adaptation, distribution and reproduction in any medium or format, as long as you give appropriate credit to the original author(s) and the source, provide a link to the Creative Commons licence, and indicate if changes were made. The images or other third party material in this article are included in the article's Creative Commons licence, unless indicated otherwise in a credit line to the material. If material is not included in the article's Creative Commons licence and your intended use is not permitted by statutory regulation or exceeds the permitted use, you will need to obtain permission directly from the copyright holder. To view a copy of this licence, visit http://creativecommons.org/licenses/by/4.0/.

\section{References}

ADP (Adubos de Portugal) (2021). Retrieved January, 2021, from https://www.adp-fertilizantes.pt/pt/agric ultura/servi\%C3\%A7o-ao-agricultor/culturas/lista-de-culturas/vinha/

Alganci, U., Kuru, G. N., Yay Algan, I., \& Sertel, E. (2019). Vineyard site suitability analysis by use of multicriteria approach applied on geo-spatial data. Geocarto International, 34(12), 1286-1299. https://doi. org/10.1080/10106049.2018.1493156 
Almeida, C., Mendonça, J.J.L., Jesus, M.R. \& Gomes, A.J. (1998). Aquíferos de Portugal. Centro de Geologia da Faculdade de Ciências da Universidade de Lisboa e Instituto Nacional da Agua, Lisboa.

Antunes, P., Karadzic, V., Santos, R., Beça, P., \& Osann, A. (2011). Participatory multi-criteria analysis of irrigation management alternatives: the case of the Caia irrigation district Portugal. International Journal of Agricultural Sustainability, 9(2), 334-349. https://doi.org/10.1080/14735903.2011.582358

Arnold, J. G., Srinivasan, R., Muttiah, R. S., \& Williams, J. R. (1998). Large area hydrologic modeling and assessment part I: model development. Journal of the American Water Resources Association, 34(1), 73-89. https://doi.org/10.1111/j.1752-1688.1998.tb05961.x

Bartzas, G., \& Komnitsas, K. (2020). An integrated multi-criteria analysis for assessing sustainability of agricultural production at regional level. Information Processing in Agriculture, 7(2), 223-232. https:// doi.org/10.1016/j.inpa.2019.09.005

Benedetto, G. (2013). The environmental impact of a Sardinian wine by partial life cycle assessment. Wine Economics and Policy, 2(1), 33-41. https://doi.org/10.1016/j.wep.2013.05.003

Berbel, J., Bournaris, T., Manos, B., Matsatsinis, N., \& Viaggi, D. (2018). Multicriteria analysis in agriculture. Springer.

Brans, J. P., \& Mareschal, B. (2005). Promethee Methods State of the Art Surveys (pp. 163-186). Springer-Verlag.

Brans, J., \& Vincke, P. (1985). A preference ranking organisation method: (The PROMETHEE method for multiple criteria decision-making). Management Science, 31(6), 647-656.

Brans, J. P., Vincke, P., \& Mareschal, B. (1986). How to select and how to rank projects: the Promethee method. European Journal of Operational Research, 24(2), 228-238. https://doi.org/10.1016/03772217(86)90044-5

CBPA - Código de Boas Práticas Agrícolas. (2018). Despacho nº1230/2018 de 5 de fevereiro de 2018 do Ministérios do Ambiente e Agricultura, Florestas e Desenvolvimento Rural. Diário da República, $2^{\mathrm{a}}$ série, $\mathrm{n}^{\circ} 25$.

Çelikbilek, Y., \& Tüysüz, F. (2020). An in-depth review of theory of the TOPSIS method: an experimental analysis. Journal of Management Analytics, 7(2), 281-300. https://doi.org/10.1080/23270012.2020. 1748528

Cinelli, M., Coles, S. R., \& Kirwan, K. (2014). Analysis of the potentials of multi criteria decision analysis methods to conduct sustainability assessment. Ecological Indicators, 46, 138-148. https://doi.org/10. 1016/j.ecolind.2014.06.011

Cogato, A., Pezzuolo, A., Sørensen, C. G., De Bei, R., Sozzi, M., \& Marinello, F. (2020). A GIS-based multicriteria index to evaluate the mechanisability potential of Italian vineyard area. Land, 9(11), 1-17. https://doi.org/10.3390/land9110469

DGADR, Direcção-Geral de Agricultura e Desenvolvimento Rural. (2013). Solos, cartografia e informação geográfica. Retrieved January, 2021, from https://www.dgadr.gov.pt/cartografia/cartas-solos-cap-usodigital

Diaz-Balteiro, L., Iglesias-Merchan, C., Romero, C., \& García de Jalón, S. (2020). The Sustainable management of land and fisheries resources using multicriteria techniques: a meta-analysis. Land, 9(10), 380. https://doi.org/10.3390/land9100380

Dinis, P. A., Pinto, P. G. A. N., Almeida, J. P. V. L., Tavares, A. M. O. S., Cabral Pinto, M. M. S., \& Pereira, A. J. S. C. (2012). Associations between lithology and land-use in a wine production region (Bairrada region, Portugal). Journal of Maps, 8(3), 271-281. https://doi.org/10.1080/17445647.2012.719291

Ferreira, C. S. S., Keizer, J. J., Santos, L. M. B., Serpa, D., Silva, V., Cerqueira, M., Ferreira, A. J. D., \& Abrantes, N. (2018). Runoff, sediment and nutrient exports from a Mediterranean vineyard under integrated production: an experiment at plot scale. Agriculture, Ecosystems and Environment, 256, 184-193. https://doi.org/10.1016/j.agee.2018.01.015

Ferreira, C. S., Veiga, A., Caetano, A., Gonzalez-Pelayo, O., Karine-Boulet, A., Abrantes, N., Keizer, J., \& Ferreira, A. J. (2020). Assessment of the Impact of Distinct Vineyard Management Practices on Soil Physico-Chemical Properties. Air, Soil and Water Research, 13, 117862212094484. https://doi.org/10. $1177 / 1178622120944847$

Garrido, J., \& Mota, T. (2011). Custos associados a uma viticultura sustentável. Jornadas regionais: Tratamentos da Vinha 2011, Portugal. (in Portuguese).

Hayshi, K. (2000). Multicriteria analysis for agricultural resource management: a critical survey and future perspectives. European Journal of Operational Research, 122(2), 486-500. https://doi.org/10.1016/ S0377-2217(99)00249-0

Herzberg, R., Pham, T. G., Kappas, M., Wyss, D., \& Tran, C. T. M. (2019). Multi-criteria decision analysis for the land evaluation of potential agricultural land use types in a hilly area of central Vietnam. Land, 8(6), 90. https://doi.org/10.3390/land8060090 
Hwang, C. L., Ching, L., \& Yoon, K. (1981). Multiple attribute decision making: methods and applications a state-of-the-art survey. Springer. https://doi.org/10.1007/978-3-642-48318-9_3

INIA-LQARS. (2000). Manual de fertilização das culturas. Ministério da Agricultura, do Desenvolvimento Rural e das Pescas, Lisbon.

Laca, A., Gancedo, S., Laca, A., \& Díaz, M. (2021). Assessment of the environmental impacts associated with vineyards and winemaking. A case study in mountain areas. Environmental Science and Pollution Research, 28(1), 1204-1223. https://doi.org/10.1007/s11356-020-10567-9

Latinopoulos, D. (2009). Multicriteria decision-making for efficient water and land resources allocation in irrigated agriculture. Environment, Development and Sustainability, 11(2), 329-343. https://doi.org/ 10.1007/s10668-007-9115-2

Mareschal, B. (2013). Visual PROMETHEE manual. VPSolutions 192p. doi: https://doi.org/10.13140/RG.2. 1.4004.3042

Mareschal, B. \& De Smet, Y. (2009). Visual PROMETHEE: developments of the PROMETHEE and GAIA multicriteria decision aid methods. In 2009 IEEE international conference on industrial engineering and engineering management (pp. 1646-1649). IEEE.

Mendas, A., \& Delali, A. (2012). Integration of multicriteria decision analysis in GIS to develop land suitability for agriculture: application to durum wheat cultivation in the region of Mleta in Algeria. Computers and Electronics in Agriculture, 83, 117-126. https://doi.org/10.1016/j.compag.2012.02. 003

Miranda, J. I. (2001). Multicriteria analysis applied to the sustainable agriculture problem. International Journal of Sustainable Development and World Ecology, 8(1), 67-77. https://doi.org/10.1080/ 13504500109470064

Modica, G., Laudari, L., Barreca, F., \& Fichera, C. R. (2014). A GIS-MCDA based model for the suitability evaluation of traditional grape varieties: The case-study of "Mantonico" grape (Calabria, Italy). International Journal of Agricultural and Environmental Information Systems, 5(3), 1-16. https://doi.org/10.4018/ijaeis.2014070101

Neitsch, S.L., Arnold, J.G., Kiniry, J.R., \& Williams, J.R., (2011). Soil and Water Assessment Tool Theoretical Documentation Version 2009, 2011. Texas Water Resources Institute Technical Report No. 406. Texas A\&M University System, Texas.

Paul, M., Negahban-Azar, M., Shirmohammadi, A., \& Montas, H. (2020). Assessment of agricultural land suitability for irrigation with reclaimed water using geospatial multi-criteria decision analysis. Agricultural Water Management, 231, 105987. https://doi.org/10.1016/j.agwat.2019.105987

Quinta-Nova, L., \& Ferreira, D. (2020). Land suitability analysis for emerging fruit crops in central Portugal using GIS. Agriculture and Forestry, 66(1), 41-48. https://doi.org/10.17707/AgricultFo rest.66.1.05

Rúbio, J. M. (2013). Conversão da vinha de Valbom para o modo de produção biológico, Report, Elvas, Portugal (in Portuguese).

Serpa, D., Nunes, J. P., Keizer, J. J., \& Abrantes, N. (2017). Impacts of climate and land use changes on the water quality of a small Mediterranean catchment with intensive viticulture. Environmental Pollution, 224, 454-465. https://doi.org/10.1016/j.envpol.2017.02.026

Serpa, D., Nunes, J. P., Santos, J., Sampaio, E., Jacinto, R., Veiga, S., Lima, J. C., Moreira, M., CorteReal, J., Keizer, J. J., \& Abrantes, N. (2015). Impacts of climate and land use changes on the hydrological and erosion processes of two contrasting Mediterranean catchments. Science of the Total Environment, 538, 64-77. https://doi.org/10.1016/j.scitotenv.2015.08.033

Seyedmohammadi, J., Sarmadian, F., Jafarzadeh, A. A., Ghorbani, M. A., \& Shahbazi, F. (2018). Application of SAW, TOPSIS and fuzzy TOPSIS models in cultivation priority planning for maize, rapeseed and soybean crops. Geoderma, 310, 178-190. https://doi.org/10.1016/j.geoderma.2017.09.012

SNIRH. (2014). Sistema Nacional de Informação de Recursos Hídricos. Dados de Base. Retrieved January, 2021 from: snirh.apambiente.pt

Talukder, B. (2016). Multi-Criteria Decision Analysis (MCDA) for Agricultural Sustainability Assessment. Theses and Dissertations (Comprehensive), 256.

Talukder, B., Blay-Palmer, A., Hipel, K., \& vanLoon, G. (2017). Elimination method of multi-criteria decision analysis (MCDA): a simple methodological approach for assessing agricultural sustainability. Sustainability, 9(2), 287. https://doi.org/10.3390/su9020287

Tzouramani, I., Mantziaris, S., \& Karanikolas, P. (2020). Assessing sustainability performance at the farm level: examples from greek agricultural systems. Sustainability, 12(7), 2929. https://doi.org/ $10.3390 /$ su 12072929

United Nations. (2019). World Population Prospects 2019: Highlights I Multimedia Library - United Nations Department of Economic and Social Affairs. United Nations. 
Van Huylenbroeck, G., \& Damasco-Tagarino, D. (1998). Analysing crop choice of Philippine vegetable farmers with multicriteria analysis. Journal of Multi-Criteria Decision Analysis, 7(3), 160-168. https://doi.org/10.1002/(SICI)1099-1360(199805)7:3\%3c160::AID-MCDA186\%3e3.0.CO;2-L

Van Meter, K. J., Basu, N. B., \& Van Cappellen, P. (2017). Two centuries of nitrogen dynamics: Legacy sources and sinks in the Mississippi and Susquehanna River Basins. Global Biogeochemical Cycles, 31(1), 2-23. https://doi.org/10.1002/2016GB005498

Van Meter, K. J., \& Basu, N. B. (2015). Catchment legacies and time lags: A parsimonious watershed model to predict the effects of legacy storage on nitrogen export. PLOS ONE, 10(5), e0125971. https://doi.org/10.1371/journal.pone.0125971

Velasquez, M., \& Hester, P. T. (2013). An analysis of multi-criteria decision making methods. International Journal of Operations Research, 10(2), 56-66. https://doi.org/10.1007/978-3-319-12586-2

Vieira A., Campos I., Rocha J., Gonzalez-Pelayo O., Verheijen F., Keizer J.J., \& Abrantes N., (2018). Contaminação de solos e águas por cobre em áreas vitícolas e aplicação de biochar para remediação do solo. In Miranda, A.I., Lopes, M., Tarelho, L., Martins, F., Roebeling, P., Coelho, M., Labrincha J. (Eds.) CIALP, Conferência Internacional de Ambiente em Língua Portuguesa (8-10/05/2018, Aveiro) Ambiente e Direitos Humanos. Universidade de Aveiro, Aveiro, (Vol. III, pp. 461-470).

WFD (2000). Directive 2000/60/EC of the European Parliament and of the Council establishing a framework for the Community action in the field of water policy, Official Journal (OJ L 327), 22 December.

Publisher's Note Springer Nature remains neutral with regard to jurisdictional claims in published maps and institutional affiliations. 